\title{
DERMATOSIS IN PATIENTS WITH CENTRAL NERVOUS SYSTEM DISORDERS
}

Pragya A. Nair, Deepak Umrigar

1. Professor. Department of Skin \& V.D, Pramukhswami Medical College, Gujarat.

2. Professor \& Head. Department of Dermatology, Govt. Medical College ,Surat, Gujarat.

\section{CORRESPONDING AUTHOR:}

Dr. Pragya A. Nair, Professor, Department of Skin \& V.D., Pramukhswami Medical College, Karamsad, Gujarat 388325.

E-mail: drpragash2000@yahoo.com

\begin{abstract}
Aim: To study the skin disease in patients with central nervous system (CNS) disorders. Methods: Total 78 patients of CNS disorders were studied, among which 49 (62.82\%) patients had skin lesions. Maximum number of patients with skin lesions had paraplegia, followed by epilepsy. Dermatophytosis was the commonest dermatosis found in $24.48 \%$ of patients followed by seborrhoeic dermatitis in $14.28 \%$ patients. Conclusion: Dermatosis in CNS disorders may be due to its treatment, immobility, congenital defects, or their common ectodermal origin.
\end{abstract}

KEYWORDS: Dermatosis, CNS disorders, paraplegia, epilepsy

INTRODUCTION: Neural changes are usually associated with skin involvement and skin changes may be associated with neuropathies. Anomalies of central nervous system (CNS) and skin occurs together frequently as they are intimately related by their common ectodermal origin. Nervous system is frequently affected in dermatological disorders than any other organ in the human body 1 .

Congenital defects affecting CNS also manifest over the skin surface. The neural changes are associated with skin involvement and skin changes may be associated with neuropathies. The neural dysfunctions of various systemic diseases are also expressed on the skin. Treatment and immobility may also be the cause of skin disease in such patients.

In the present study CNS disorders like epilepsy, hemiplegia, paraplegia, quadriplegia, parkinsonism, head injury, trigeminal neuralgia and bells palsy were studied and their association with various skin disorders were noted.

AIM: To study the skin diseases in patients with CNS disorders.

MATERIAL AND METHOD: Subject group comprised of 78 patients with various CNS disorders viz., epilepsy, hemiplegia, paraplegia, Parkinson's disease and Bell's palsy who were admitted to the hospital or attended the OPD of a teaching institute.

Complete history including chief complaints like convulsions, consciousness, tingling, inability to move limbs were noted. Past history regarding similar episodes, any surgery, accidents, drug reaction was asked. Complaints regarding skin lesions were noted and the form of treatment taken was inquired.

Patients were examined for CNS involvement:

1. Higher Functions for consciousness, behavior, intelligence, memory, orientation, hallucinations, delusions and speech. 
2. Cranial Nerves for their proper function

3. Reflexes- superficial and deep

4. Gait

5. Meningeal signs

6. Sensations

7. Motor system: like power and tone.

All patients were examined in proper day light after taking prior consent for skin lesions.

Routine investigations were done in all patients while VDRL, chest X-ray, CSF, CT scan, MT and EEG were done whenever required. KOH smear, Tzank smear and skin biopsy were done in relevant cases only.

RESULTS AND DISCUSSION: Present study included 78 patients of Central Nervous System disorders between the age of 1 year to 79 years. Number of males were 55(70.5\%) and females $23(23.48 \%)$. Maximum no of patients were 14 in age group 41-50 years. Youngest patient was of 1 year old and the oldest patient was of 79 years old.

Distribution of patients in various CNS disorders with skin lesions (Table. 1), shows that out of 78 patients 49 patients had skin lesions predominantly in paraplegia (40.8\%), followed by epilepsy(22.4\%).

\begin{tabular}{|l|c|c|c|}
\hline \multicolumn{4}{|c|}{ Table. 1: Distribution of patients in various CNS disorders with skin lesions } \\
\hline CNS disorders & Total & No. of patients having skin lesion & \% \\
\hline Epilepsy & 20 & 11 & 22.4 \\
\hline Hemiplegia & 15 & 7 & 14.2 \\
\hline Paraplegia & 24 & 20 & 40.8 \\
\hline Parkinsonism & 6 & 4 & 8.16 \\
\hline Quadriplegia & 2 & 1 & 2.04 \\
\hline Head injury & 2 & 1 & 2.04 \\
\hline Trigeminal neuralgia & 4 & 3 & 6.12 \\
\hline Bell's palsy & 5 & 2 & 4.08 \\
\hline Total & 78 & 49 & 62.82 \\
\hline
\end{tabular}

Of 20 cases of epilepsy 11 patients had skin lesions (Table. 2).

\begin{tabular}{|l|l|}
\hline Table.2 :Dermatosis in Epilepsy \\
\hline Dermatosis & Total \\
\hline Café-au-lait spots & 2 \\
\hline Adenoma sebaceum & 2 \\
\hline Acne vulgaris & 2 \\
\hline Leuconychia & 1 \\
\hline Gum hyperplasia & 1 \\
\hline Linear scar & 1 \\
\hline Tinea cruris & 2 \\
\hline Total & 11 \\
\hline
\end{tabular}

Fitzpatrick TB et al $^{2}$ found ash-leaf- macules in 3 patients of tuberous sclerosis with history of epilepsy among which one had only adenoma sebaceum and the other had adenoma sebaceum, shagreen patch with intracranial calcification. Yakovlez and Gultri ne ${ }^{3}$ stated that $10 \%$ of male 
epileptics in state hospitals had cutaneous manifestations of neurofibromatosis. Patients on anticonvulsants like carbamazepin, phenytoin and barbiturates in E.Swart and J Lochner ${ }^{4}$ study had acne, leuconychia, linear scars, papular urticaria, verruca vulgaris, tinea pedis and hirsutism. In present study 2 patients with epilepsy had café-au-lait spot, one child along with it had giant pigmented macule, while two patients had adenoma sebaceum. Of patients on antiepileptics 2 had developed acne vulgaris, 1 gum hypertrophy, 1 linear scar and 1 leuconychia had developed.

Laidlaw $\mathrm{J}^{5}$ states that massive activation of both sympathetic and parasympathetic systems occurs during generalized tonic seizures leading to vasoconstriction of arterioles of nailmatrix ,which leads to parakeratosis and leuconychia.

Of 15 cases of Hemiplegia patients 7 had skin lesions (Table. 3).

\begin{tabular}{|l|l|}
\hline \begin{tabular}{l}
$|l|$ \\
Table.3 : Dermatosis in \\
\hline Dermatosis
\end{tabular} & Total \\
\hline $\begin{array}{l}\text { Blisters / contact } \\
\text { dermatitis }\end{array}$ & 2 \\
\hline Bed sores & 1 \\
\hline $\begin{array}{l}\text { Tinea cruris \& } \\
\text { corporis }\end{array}$ & 3 \\
\hline Urticaria & 1 \\
\hline Total & 7 \\
\hline
\end{tabular}

Mysterious blisters, unrelated to development of pressure sores or local trauma occurred in 3 hemiplegic in a study by T. G .J udge and N. H Misbet ${ }^{6}$. This trophoneurotic blisters is due to alteration in any tissue, due to failure of nutrition from defective nerve influences.

Freeman and Roza7 reported 2 cases 1 with hemiplegia and other with quadriplegia had bullous lesions. Impairment of vasomotor reflexes in comatose state and local vasodilatation is the cause. Morton and Meharen ${ }^{8}$ found that in 64 elderly paraplegics $1 / 3$ had pressure sores. In the present study 2 patients of paraplegia, one due to metastatic disease of bone and other due to fracture dislocation had bed sores. It seems to be due to sensory dysfunction and disuse atrophy.

William B. Reed 9 found 5 patients having nummular eczema on paralyzed side compared to 3 patients as in our study. He found a case with generalized allergic contact dermatitis above and below the level of complete transection at T11 level. Walshe $\mathrm{M}^{10}$ found $50 \%$ of 84 patients with contact dermatitis in spinal cord injury. Present study reported 2 cases of contact dermatitis along with bedsores, may be due to betadine solution used for washing the sores.

Of 24 cases of Paraplegia patients 20 had skin lesions (Table. 4) and of 2 patients of Quadriplegia, 1 had seborrhic dermatitis with tinea cruris. 


\begin{tabular}{|l|l|}
\hline \multicolumn{2}{|l|}{ Table. 4: Dermatosis in Paraplegia } \\
\hline Dermatosis & Total \\
\hline Bed sores & 2 \\
\hline Eczema & 3 \\
\hline Seborrhic dermatitis & 2 \\
\hline Intertrigo & 4 \\
\hline $\begin{array}{l}\text { Neurofibromas/ } \\
\text { Café-au-lait spots } \\
\text { axillary freckling }\end{array}$ & 2 \\
\hline Neuropathic ulcer & 2 \\
\hline Tinea cruris & 3 \\
\hline $\begin{array}{l}\text { Dry scaling lesion } \\
\text { with ulcer over left } \\
\text { dorsum of foot }\end{array}$ & 1 \\
\hline $\begin{array}{l}\text { Scar of lupus } \\
\text { vulgaris }\end{array}$ & 1 \\
\hline Total & 20 \\
\hline
\end{tabular}

Seborrheic dermatitis is seen in 20 out of 43 quadriplegic and 5 paraplegic according to William B. Reed ${ }^{9}$. In the present study 2 with paraplegia and 1 with quadriplegia had seborrheic dermatitis. 3 patients with fracture dislocation having paraplegia had tinea cruris and 4 had intertrigo, which may be due to increased sweating and immobilization or warm and humid climate. One patient with paraplegia due to Pott's spine had dry scaly pellagramatous infiltration of skin over forearm, leg and ulcer over left foot. Patient had upper zone infiltration suggestive of tuberculosis on chest x-ray and was on antitubercular therapy.

Patrick J Kelly,Mark B. et al ${ }^{11}$ reviewed 47 cases of neurotrophic ulcers of which 6 were due to syringomyelia and 4 had old spinal cord injury. Present study showed 2 cases of neuropathic ulcers in syringomyelia, 1 operated 10 years back developed weakness of both lower limbs with ulcers over heel, other had an ulcer over head of $5^{\text {th }}$ metatarsal bone. Changes of degeneration with peripheral sensory impairment can be the cause for the same.

Ricarrdi and Elichner ${ }^{12}$ studied 238 cases of neurofibromatosis, 15 had spinal neurofibroma, and 29 had scoliosis. In the present study 2 patients of paraplegia had multiple neurofibromas with café-au-lait spots and axillary freckles, one among them had spinal neurofibromas, and one had scoliosis.

Of 6 Parkinsonism patients 4 had skin lesions, seborrheic dermatitis and Tinea corporis in 3 and 1 respectively. Colm Forst ${ }^{13}$ noted seborrheic dermatitis in patients with Parkinsonism. Pronounced seborrhoea due to increased size of the sebaceous glands may be the cause. J L Burton et al ${ }^{14}$ found that 5 patients with Parkinsonism on levodopa showed dramatic response in seborrheic dermatitis after 3 weeks. Pituitary plays an important role in control of sebum secretion and L-dopa exerts its effect on sebum production by modifying pituitary secretion. Though Parkinson's disease is associated with seborrhea and seborrheic dermatitis, it's treatment with L-dopa which reduces sebum secretion if it is in excess but has no effect if the sebum secretion is normal, it has been suggested that the increased sebum level in patients of Parkinson's disease have permissive effect on growth of Malassezia. ${ }^{15}$ In present study 3 patients of Parkinsonism had seborrheic dermatitis and after 4 weeks on levodopa they were found to have less greasy skin. 
Out of 2 patients of head injury 1 had diffuse loss of scalp hair. Tarnow G.16 found all the patients of head injury to have diffuse loss of hair from scalp.

Bettly FR and Mater $\mathrm{RH}^{17}$ reported a case of seborrheic dermatitis following Bell's palsy unilaterally. In the present study out of 5 patients of Bell's palsy 1 had seborrheic dermatitis and 1 had scar of herpes zoster which may be the cause of Bell's palsy and increase in pool of sebum may be the cause of seborrheic dermatitis.

Among 4 patients of Trigeminal neuralgia 3 had skin lesions, 1 had Herpes simplex and 2 had Tinea corporis with Tinea cruris. H Burdick and John R Haserick ${ }^{18}$ studied 148 patient with trigeminal neuralgia who had intracranial operations, about $1 / 3$ developed herpes simplex on the skin supplied by the manipulated nerve. In the present study 1 case of trigeminal neuralgia had herpes simplex Operative trauma to the nerve played an integral part in development of herpes simplex. Dermatophytosis found in 2 was co-accidental.

CONCLUSION: In our study of 78 patients with various CNS disorders, 49 (62.82\%) had dermatosis. Dermatophytosis was most common $24.48 \%$. Warm and humid climate along with immobilization and inability to maintain proper hygiene may be the cause for it. Second commonest dermatosis was seborric dermatitis, more common in Parkinsonism, increased sebum production or inability to maintain the hygiene may be the cause. Dermatosis due to anticonvulsant therapy was seen in 5 cases $(10.02 \%)$ in the form of a acne vulgaris, leuconychia, gum hypertrophy and linear scar, offending drug found was carbamazepine and phenytoin.

Since skin and nervous system are intimately related by the common ectodermal origin anomalies of both occur together in the midline. Stress must be placed on recognition of importance of midline cutaneous abnormalities that may be associated with occult spinal disorders. Routine dermatological examination should be performed in all patients with CNS disorders. More studies are required to see for incidence and nature of association.

\section{REFERENCES:}

1. C.B. Archer \& D.J. Eedy: The Skin and the Nervous System. Rook's textbook of dermatology. $7^{\text {th }}$ e: $60.1-24,2006$

2. Fitzpatrick TB, Szabó G, Hori Y, Simone AA, Reed WB, Greenberg MH. White leaf-shaped macules. Earliest visible sign of tuberous sclerosis. Arch Dermatol. 1968 Jul;98(1):1-6.

3. Yakovlez PI, Gultrie RH. The brain in neurofibromatosis. Arch Neurol Psychiat Chicago; 1931:26;1145.

4. Swart E, Lochner JD. Skin conditions in epileptics. Clin Exp Dermatol. 1992 May;17(3):169-72.

5. Laidlaw J , Richens A . Oxley J (eds) A textbook of epilepsy, $3^{\text {rd }}$ Edn, Churchill Livingstone, New York, 1988, 222 .

6. Judge TG, Nisbet NH. Trophoneurotic blisters in elderly hemiplegics. Lancet 1967;1(7494):811-2.

7. Freeman DM, Raza M. Bullous lesions in acute barbiturate intoxication. Br Med J. 1965;1(5448):1495-6.

8. Norton D, McLaren R, Exton-Smith AN. An Investigation of Geriatric Nursing Problems in Hospital. Edinburgh, New York: Churchill Livingstone; 1975.

9. Reed WB, Pidgeon J, Becker SW. Patients with spinal cord injury. Clinical cutaneous studies. Arch Dermatol. 1961;83:379-85. 
10. Walshe MM. Contact dermatitis in a spinal injuries centre. Contact Dermatitis. 1975;1(1):3-6.

11. Patrick J. Kelly, M.D. Mark B. Coventry, M.D. Neurotrophic ulcers of the feet: review of forty-seven cases. JAMA. 1958;168(4):388-393.

12. Riccardi VM ,Eichner JE (1986) : Neurofibromatosis, phenotype, natural history \& pathogenesis. Baltimore John Hopkins University Press

13. Cohn T - Encephalitis ohne Lethargie während der Grippe-epidemie. Neurol Zbl 38:260, 1920.

14. Burton JL, Shuster S. Effect of L-dopa on seborrhoea of parkinsonism. Lancet. 1970;2(7662):19-20.

15. Valia RG. Etiopathogenesis of seborrheic dermatitis. Indian J Dermatol Venereol Leprol. 2006;72(4):253-5.

16. Tarnow G, Rabe W. Central regulation of hair nutrition, Hypertrichoses and alopecias following severe skull-brain injuries. Nervearzt. 1969 May;40(5):210-5.

17. Bettley FR, Marten RH. Unilateral seborrheic dermatitis following a nerve lesion. AMA Arch Derm.1956;73(2):110-115,1956.

18. Burdick KH, Haserick JR, Gardener WJ. Herpes simplex following decompression operations for trigeminal neuralgias. Attempts to modify by local use of hydrocortisone preparations. Arch Dermatol.1960:81(6):919-21 